\title{
Progress Toward Increasing Intake of Dietary Nutrients from Vegetables and Fruits: The Case for a Greater Role for the Horticultural Sciences
}

\author{
Philipp W. Simon ${ }^{1}$ \\ USDA-ARS, Vegetable Crops Research Unit, Department of Horticulture, University \\ of Wisconsin-Madison 1575 Linden Drive, Madison, WI 53706
}

Additional index words. convenience, flavor, human health, nutrition, phytonutrients, vitamins

\begin{abstract}
Diet is implicated globally in the cause and severity of many diseases, including cancer, heart disease, and diabetes, and a large body of medical evidence indicates that consumption of healthier foods can alleviate both the incidence and severity of not only these diseases, but also obesity, which is a causal factor for many chronic diseases. The 2010 Dietary Guidelines for Americans indicated that several nutrients are underconsumed in the United States, including folate, magnesium, potassium, dietary fiber, and vitamins A, C, and $\mathrm{K}$. Vegetables and fruits are major sources of several of these micronutrients and minerals as well as many other phytonutrients. Despite these health benefits, vegetable and fruit intake by U.S. consumers is significantly lower than recommended by dietary guidelines (less than $40 \%$ of recommended intake) and has not risen in the past decade. Collaborations between horticultural plant breeders, production and postharvest scientists with food scientists, nutritionists, medical scientists, marketing specialists, and social scientists are needed to develop plans and take action to stimulate increased vegetable and fruit intake. Increased intake may have a positive impact not only on the health of consumers, but would also increase the economic value of horticultural commodities and raise the profile of horticultural sciences. Horticultural approaches to address this important challenge, and opportunity, must be developed.
\end{abstract}

\section{LACKLUSTER TRENDS IN VEGETABLE AND FRUIT INTAKE}

"Increase vegetable and fruit intake" is the first recommendation presented in the "Foods and Nutrients to Increase" chapter of the 2010 Dietary Guidelines for Americans (U.S. Department of Agriculture and U.S. Department of Health and Human Services, 2010). The reasons for this recommendation are that 1) vegetables and fruits are major dietary sources of several vitamins and provitamins (especially provitamin A, vitamin $\mathrm{C}$, and vitamin $\mathrm{K}$ ), folate, minerals (especially magnesium and potassium), and dietary fiber that are underconsumed or "shortfall" by Americans; 2) consumption of vegetables and fruits is associated with a reduced risk of certain chronic diseases (especially cardiovascular disease, including heart attacks and stroke); and 3) most vegetables and fruits are relatively low in calories when prepared without added fats or sugar, thus helping consumers achieve and maintain a healthy weight. The medical and nutritional literature provides a large body of evidence that indicates consumption of vegetables and fruits contributes significantly to human health (He et al., 2007; Hu, 2003; Hung et al., 2004; Simon et al., 2009; U.S. Department of Agriculture, Agricultural Research Service, 2012; World Health Organization, 2003). The shortfall nutrients noted previously as well as other vitamins, minerals, and phytonutrients such as flavonoids and non-provitamin A carotenoids

\footnotetext{
Received for publication 4 Sept. 2013. Accepted for publication 9 Dec. 2013.

This paper was part of the colloquium "Advances in Breeding Vegetables and Fruits for Enhanced Nutritional Content" held 31 July 2012 at the ASHS Conference, Miami, FL, and sponsored by the Vegetable Breeding Working Group.

${ }^{1}$ To whom reprint requests should be addressed; e-mail philipp.simon@ars.usda.gov.
}

(e.g., lycopene and lutein) (Murphy et al., 2012) and chemoprotective sulfur-containing compounds often found in Allium and Brassica vegetables (Mithen, 2008) are abundant in many vegetables and fruits. Failure to improve our modern eating habits has a large negative impact on our societal health with more than half of the U.S. and most Western countries suffering from diet-related chronic diseases (Cordain et al., 2005). Furthermore, the economic impact of these diseases contributes significantly to the staggering healthcare costs borne by modern society.

Despite the documented benefits and strong recommendations for increased intake of vegetables and fruits, Casagrande et al. (2007) noted no positive response by consumers to these recommendations. They noted that from 1988 to $1994,27 \%$ of adults met the U.S. Department of Agriculture guidelines for the number of daily servings of fruit consumed, and that from 1988 to 2002, there was no significant change $(28 \%)$ in that percentage. For vegetables, they observed decreased consumption trends in that period of time, from $35 \%$ to $32 \%$. Similar low current intake values were noted by Guenther et al. (2006) and Kimmons et al. (2009). Low intake of vegetables and fruits is not a problem unique to the United States because Food and Agricultural Organization of the United Nations/World Health Organization surveys confirm similar human health risks are associated with low vegetable and fruit intake in many parts of the world (reviewed by Pomerleau et al., 2004).

\section{FACTORS UNDERLYING LOW VEGETABLE AND FRUIT INTAKE, AND INTERVENTIONS TO INCREASE CONSUMPTION}

A wide range of explanations for low vegetable and fruit intake has been presented. These include limited availability on restaurant, especially fast food, menus; high cost of vegetables and fruits in restaurants and grocery stores; limited access to restaurants and grocery stores in disadvantaged neighborhoods ("food deserts"); strong advertising campaigns for fast foods but not for vegetables and fruits; personal and cultural barriers reducing preference; slow, messy, and complicated preparation of vegetables and fruits for consumption in the home; confusing nutritional guidelines; and inadequate consumer education (Casagrande et al., 2007; Heber and Bowerman, 2001).

Several intervention programs have been developed to encourage increased vegetable and fruit intake. These include interventions at many levels ranging from the individual, to the community, to populations, to policy and environmental interventions. Most of these intervention plans included counseling, education, or promotional campaigns (Epstein et al., 2001; Pomerleau et al., 2004, 2005; Resnicow et al., 2001). Most interventions had a positive effect, but in some cases, the effect was small and, in many, the effect did not persist. More recently the Centers for Disease Control and Prevention (Centers for Disease Control and Prevention, 2011) suggested a broader approach involving food policy councils (diverse stakeholders from public, private, and nonprofit sectors including representatives from the nutrition, health, education, policy, commerce, and agriculture communities) to promote improved consumer retail and food service access, farm-to-institution connections, communitysupported agriculture, and home gardening.

\section{AN EXPANDED ROLE FOR THE HORTICULTURE COMMUNITY TO SUPPORT EFFORTS TO INCREASE VEGETABLE AND FRUIT INTAKE}

The horticulture industry, educators, and researchers have had an obvious role in influencing vegetable and fruit consumption 
through their direct involvement in breeding, growing, storing, processing, and marketing the vegetable and fruit crops that are receiving this heightened level of interest and attention by nutritionists and health scientists. This situation provides an excellent opportunity for the horticultural sciences to raise their profile in the scientific community as well as with the consuming public. Some horticultural organizations such as the American Society for Horticultural Science $(<\mathrm{http}: / /$ www.ashs.org $>$ ) and the Asian Vegetable Research and Development Center-The World Vegetable Center $(<\mathrm{http}: / /$ www.avrdc.org $>)$ are already taking action to heighten the public awareness of vegetables and fruits, but there is more that could be done. Several examples of what horticulturists could do to support efforts to increase vegetable and fruit intake are provided.

Plant breeding. Plant breeders of vegetable and fruit crops could increase their efforts to select for improved consumer traits (e.g., flavor, convenience, nutritional value) as a routine part of the breeding process. They could evaluate breeding stocks in consumer panels and better highlight consumer quality in their descriptions of advanced breeding stocks and germplasm releases, including data summarizing the flavor and content of key nutrients.

Although nutritional value is of interest for consumers, flavor is likely even more important (e.g., Drewnowski and GomezCarneros, 2000). Flavor often varies widely among cultivars and breeding stocks, and although many vegetable and fruit breeders evaluate flavor, an expanded effort to evaluate and publicize flavor in breeding stocks may stimulate heightened consumer interest. Flavor, texture, and general organoleptic quality are among the more challenging traits to evaluate in diverse breeding populations, and gathering data to document consumer quality as part of the process of releasing germplasm is often not a routine activity, but genotype is often the largest contributor to variation in flavor (Pattee, 1985) suggesting an important role for plant breeders in flavor improvement. Many fruit crop breeders and some vegetable breeders rigorously evaluate organoleptic quality in breeding stocks, but vegetable and fruit breeders who are not already doing so will often need to collaborate with flavor and sensory evaluations scientists to generate publishable organoleptic quality information. Optimal field production or postharvest conditions or processing methodologies can rarely, if ever, improve undesirable organoleptic quality conditioned by genotype, so efforts to increase vegetable and fruit intake must start with plant breeding. Greater focus on flavor in information provided to consumers with the release of new vegetable and fruit germplasm and finished varieties could stimulate increased interest and intake for some consumers.

Plant breeding efforts to increase the nutrient content of horticultural crops has received some attention, and it is worth noting that genetic variation for mineral and other micronutrient content is sufficient to combine high nutrient content with adequate yield in vegetables and fruits (Simon et al., 2009) as has been undertaken for wheat (Cakmak et al., 2004), potatoes (White et al., 2009), and carrots (Simon et al., 2009). Breeding for increased nutritional content is not without potential barriers because it requires additional resources to perform nutrient analysis and may not be feasible if increased nutrient content is genetically correlated with reduced yield (Luby and Shaw, 2009). Given ongoing research applying genomic tools to better understand the complex genetic basis of yield and accumulation of many nutrients in modern vegetable and fruit breeding programs, the combination of increased yield and increased nutritional value should be possible, and, in fact, breeding efforts have resulted in yield-competitive cultivars with increased nutrient content for several horticultural and agronomic crops (Simon et al., 2009). Although selecting for nutritional quality in large breeding populations can be prohibitively expensive, an evaluation of a few key nutrients and phytonutrients in germplasm that is about to be released is relatively affordable. Furthermore, highlighting new germplasm releases that contain high nutritional content may raise the interest of consumers. Side-by-side comparisons of new germplasm releases with major cultivars grown today are essential in describing nutritional quality. Expanding these comparisons to include a range of early major cultivars spanning recent decades can provide interesting historical insights into changes in nutritional quality of vegetable and fruit crops over time. There is evidence that the nutrient content of vegetables and fruits has declined in recent decades (Davis, 2009, 2011; Davis et al., 2004), similar to the downward trend or "dilution effect" in mineral concentration of wheat (Fan et al., 2008). The rationale for drawing firm conclusions for vegetable nutrient content based on historical trends has only been evaluated in very few side-by-side comparisons of early and recent cultivars (Farnham et al., 2011; Farnham and Grusak, 2014; White et al., 2009), so these historical trends warrant further evaluation. Given the interest in heirloom vegetables and fruits, plant materials for those comparisons may be available, presuming recent seed increases of seed-propagated early cultivars have not shifted nutrient content by modern breeders.

Although plant breeding for increased nutritional content may be feasible, and can raise consumer attention, it is important to note that increased nutritional content is not a trait that, by itself, can stimulate increased total vegetable and fruit intake. Flavor, appearance, convenience, and other traits more readily observed and appreciated by consumers must also be improved for vegetables and fruits with increased nutritional content to have an impact on consumer health.

Field trials. Vegetable and fruit nutritional quality and flavor can also very widely across growing locations and production techniques (Pattee, 1985; Pelayo-Zaldívar, 2011). Some commodities highlight flavor in regional trials. For example, mild onion flavor is a regular topic raised by onion trial managers that has penetrated the media to consumers. Increased evaluation and reporting of flavor in all vegetable and fruit crops may raise grower and public awareness of cultivars, growing locations, and production techniques that influence consumer quality.

Horticulture extension specialists and plant breeders regularly carry out field trials to evaluate new cultivars and breeding stocks, and they usually invite commodity-specific industry representatives and others involved with the commodity to the trials. Local publicity of trials sometimes is excellent, but often is small or nil. Public announcement of trials in local papers is often free and may attract local press and small-scale growers (e.g., in community-supported agriculture, home gardens). Although some trial managers gather no feedback on the performance of trial entries from attendees, many do. If collected, results of these trials are usually published but only rarely are they disseminated beyond participants and/or posted at a web site. Furthermore, the results are generally tallied but only rarely summarized in narrative fashion by the trial manager. A simple narrative account summarizing the conditions of the trial and pointing out high-performing entries, novel traits, and other interesting results may enliven a trial report and potentially draw the attention of the press and consumers. For some crops, trials include unusual or novel entries as well as standard cultivars. Selected produce, typical and novel, from a trial can be displayed at local farmers' markets and images of the crop posted online may stimulate interest not only by trial participants, but also small- and largescale growers and the public.

New vegetable and fruit products. Processing of vegetables and fruits can provide an additional avenue to develop new products for consumers to increase intake. Vegetable juices have been demonstrated as one effective way to stimulate intake (Shenoy et al., 2010). "Lightly processed" baby carrots, celery sticks, pepper strips and diced melons, pineapples, and other vegetables and fruit have developed rapidly as value-added products to provide consumers with a more convenient source of vegetable and fruits that ultimately may stimulate intake. New fresh and processed products may be more appealing to consumers and the incorporation of vegetables into breads and meat sauces to "hide" them has been suggested (Blatt et al., 2011). Increased collaboration between horticulturists and food scientists may stimulate the development of new, high-value convenience products, and alternative vegetable and fruit products may potentially increase intake.

Local agriculture, local food, and organic agriculture. Some of the promotional targets proposed by the Centers for Disease Control and Prevention (2011) to increase vegetable and fruit intake involve local production of crops that is receiving increased attention by 
horticultural scientists: home gardening, community-supported agriculture, and farm markets. In the 2005-10 period, between $22 \%$ and $27 \%$ of the U.S. households reported "vegetable gardening," $10 \%$ to $13 \%$ reported "fruit trees," and 5\% to 8\% reported "growing berries" as recreational activities according to survey information gathered by the National Gardening Association and published by the U.S. Census Bureau (2012). The Garden Writers Association (2013) reported that $69 \%$ of the U.S. households with a yard or garden planned on growing vegetables in 2013 with $73 \%$ of that group noting better quality, taste, and nutrition as the reason they grow their own. Communitysupported agriculture (CSA) involved only 50 CSA farms in the United States in 1990, but that number grew to over 1900 by 2008 with even more growth since then. In a similar timeframe, farmers markets have increased in number by $53 \%$ between 2000 and 2007 (Brown and Miller, 2008). The rise in popularity of organic agriculture (Greene, 2013) parallels that of CSAs and local agriculture. Organic production practices are often an integral part of CSAs and other local agriculture, and vegetables and fruits accounted for $43 \%$ of total organic sales in 2012. Local production of vegetables and fruits in CSAs and organic production provides an opportunity to test new ideas in crop production, preparation, and marketing and to also obtain feedback from local consumers. Horticulturists have played a significant role in the development of local agriculture, and that feedback from local consumers can provide important insights into better understanding consumer attitudes accounting for low vegetable and fruit intake and can recommend actions horticulturists might undertake to increase intake of dietary nutrients from vegetables and fruits.

\section{CROP PRODUCTION INCREASES NEEDED TO MEET INCREASED VEGETABLE AND FRUIT INTAKE}

In addition to the positive effects that increased vegetable and fruit intake may have on human health and reduced healthcare costs, Buzby et al. (2006) pointed out that adoption of the Dietary Guidelines would also have a very large direct impact on horticultural crop production. They estimated that to fully meet the Dietary Guidelines, a 31\% increase in vegetable consumption and $132 \%$ fruit consumption increase would be needed. To meet these increased consumption goals, Buzby et al. (2006) estimated that an additional 3.6 M/ha of vegetable production and $1.7 \mathrm{M} /$ ha of fruit production would be needed in the United States. Although intake trends do not suggest these levels of consumption any time soon, increased intake clearly will have positive consequences for horticultural crop producers and at the same time, it will present significant challenges in providing adequate production land and natural resources. Additional evaluation of benefits and costs of increased intake beyond the general data presented by Buzby et al. (2006) will be of interest, for example by crop, by production area or with the development of new vegetable and fruit products.

\section{CONCLUSIONS AND FUTURE DIRECTIONS}

Increased intake of vegetables and fruits is strongly encouraged by nutritionists and health professionals but consumption trends indicate that consumers are not responding to these recommendations. Reasons for this lack of response are not obvious and are likely complex, requiring multiple approaches to pursue and achieve positive results. Both improved consumer health and increased horticultural crop production values would be realized with increased intake of vegetables and fruits, and horticulturists should play a more active role in this important effort. Increased research focusing on improving consumer quality by horticultural plant breeders and production and postharvest scientists is needed. As that research progresses, more information about consumer quality resulting from that research needs to be communicated to consumers to stimulate consumption of more vegetable and fruits. Development of new vegetable and fruit products and preparation approaches by horticultural scientists and food scientists to enhance consumer quality, including flavor and convenience, will expand food choices available to consumers. Local agriculture operations such as home gardeners, community-supported agriculture, and farm markets provide not only a conduit for testing and deploying new horticultural crop cultivars and production technologies, but also provide a sounding board for horticultural scientists to obtain expanded feedback on consumer issues. Success in increasing intake of vegetables and fruits will require not only greater innovation, communication, and consumer education by horticulturists, but also a larger collaborative effort with nutritional and health scientists, marketing specialists, and social scientists. Although some efforts have been undertaken to increase vegetable and fruit intake, numerous challenges and opportunities remain.

\section{Literature Cited}

Blatt, A.D., L.S. Roe, and B.J. Rolls. 2011. Hidden vegetables: An effective strategy to reduce energy intake and increase vegetable intake in adults. Amer. J. Clin. Nutr. 93:756-7763.

Brown, C. and S. Miller. 2008. The impacts of local markets: A review of research on farmers markets and community supported agriculture (CSA). Amer. J. Agr. Econ. 90:1298-1302.

Buzby, J.C., H. Farah Wells, and G. Vocke. 2006. Possible implications for U. S. agriculture from adoption of select dietary guidelines. U.S. Dept. Agric., Economic Research Report No. 31.

Cakmak, I., A. Torun, E. Millet, M. Feldman, T. Faima, and A. Korol. 2004. Triticum dicoccoides: An important genetic resource for increasing zinc and iron concentration in modern cultivated wheat. Soil Sci. Plant Nutr. 50:1047-1054.

Casagrande, S.S., Y. Wang, C. Anderson, and T.L. Gary. 2007. Have Americans increased their fruit and vegetable intake? The trends between 1988 and 2002. Amer. J. Prev. Med. 32:257293.

Centers for Disease Control and Prevention (CDC). 2011. Strategies to prevent obesity and other chronic disease: The CDC guide to strategies to increase the consumption of fruits and vegetables. U.S. Dept. Health Human Serv., Atlanta, GA.

Cordain, L., S.B. Eaton, A. Sebastian, N. Mann, S. Lindeberg, B.A. Watkins, J.H. O'Keefe, and J. Brand-Miller. 2005. Origins and evolution of the Western diet: Health implications for the $21^{\text {st }}$ century. Amer. J. Clin. Nutr. 81:341-353.

Davis, D.R. 2009. Declining fruit and vegetable nutrient composition: What is the evidence? HortScience 44:15-19.

Davis, D.R. 2011. Impact of breeding and yield on fruit, vegetable, and grain nutrient content, p. 127-150. In: Jenks, M.A. and P. Bebli (eds.). Breeding for fruit quality. Wiley Press, West Sussex, UK

Davis, D.R., M.D. Epp, and H.D. Riordan. 2004 Changes in USDA food composition data for 43 garden crops, 1950 to 1999. J. Amer. Coll. Nutr. 23:669-682.

Drewnowski, A. and C. Gomez-Carneros. 2000. Bitter taste, phytonutrients, and the consumer: A review. Amer. J. Clin. Nutr. 72:1424-1435.

Epstein, L.H., C.C. Gordy, H.A. Raynor, M. Beddome, C.K. Kolanowski, and R. Paluch. 2001. Increasing fruit and vegetable intake and decreasing fat and sugar intake in families at risk for childhood obesity. Obes. Res. 9:171-178.

Fan, M.S., F.J. Zhao, S.J. Fairweather-Tait, P.R. Poulton, S.J. Dunham, and S.P. McGrath. 2008. Evidence of decreasing mineral density in wheat grain over the last 160 years. J. Trace Elem. Med. Biol. 22:315-324.

Farnham, M.W. and M.A. Grusak. 2014. Assessing nutritional changes in a vegetable over time: Issues and considerations. HortScience 49:127131.

Farnham, M.W., A.P. Keinath, and M.A. Grusak 2011. Mineral concentration of broccoli florets in relation to year of cultivar release. Crop Sci. 51:2721-2727.

Garden Writers Association. 2013. April gardening trends research report. $<$ http://www. gardenwriters.org/gwa.php?p=gwafoundation/ surveys_gardentrends.html $>$.

Greene, C. 2013. Organic production. USDA, Economic Research Service, Oct. 2013. <http://www. ers.usda.gov/data-products/organic-production. aspx\#.UqHrXOKrRkg>.

Guenther, P.M., K.W. Dodd, J. Reedy, and S.M. Krebs-Smith. 2006. Most Americans eat much less than recommended amounts of fruits and vegetables. J. Amer. Diet. Assoc. 106:1371-1379.

He, F.J., C.A. Nowson, M. Lucas, and G.A. MacGregor. 2007. Increased consumption of fruit and vegetables is related to a reduced risk of coronary heart disease: Meta-analysis of cohort studies. J. Hum. Hypertens. 21:717-728.

Heber, D. and S. Bowerman. 2001. Applying science to changing dietary patterns. J. Nutr. 131:3078S-3081S.

Hu, F.B. 2003. Plant-based foods and prevention of cardiovascular disease: An overview. Amer. J. Clin. Nutr. 78:544S-551S.

Hung, H.C., K.J. Joshipura, R. Jiang, F.B. Hu, D. Hunter, A. Smith-Warner, G.A. Colditz, B. Rosner, D. Spiegelman, and W.C. Willett. 2004. Fruit and vegetable intake and risk of major chronic disease. J. Natl. Cancer Inst. 96:1577-1584.

Kimmons, J., C. Gillespie, J. Seymour, M. Serdula, and H.M. Blanck. 2009. Fruit and vegetable 
intake among adolescents and adults in the United States: Percentage meeting individualized recommendations. Medscape J. Medicine $11: 26$.

Luby, J.J. and D.V. Shaw. 2009. Plant breeder's perspective on improving yield and quality traits in horticultural food crops. HortScience 44:20-22.

Mithen, R. 2008. Sulfur-containing compounds, p. 25-45. In: Crozier, A., M.N. Clifford, and H. Ashihara (eds.). Plant secondary metabolites: Occurrence, structure and role in the human diet. John Wiley and Sons, New York, NY.

Murphy, M.M., L.M. Barraj, D. Herman, X. Bi, R. Cheatham, and R.K. Randolph. 2012. Phytonutrient intake by adults in the United States in relation to fruit and vegetable consumption. J. Acad. Nutr. Dietetics 112:222229.

Pattee, H.E. 1985. Evaluation of quality of fruits and vegetables. 1985. AVI Publ. Co., Westport, CT.

Pelayo-Zaldívar, C. 2011. Environmental effects on flavor changes, p. 73-92. In: Hui, Y. H., F. Chen, L.M. Nollet, R.P.F. Guiné, O. MartínBelloso, M.I. Mínguez-Mosquera, G. Paliyath, F.L.P. Pessoa, J.-L. Le Quéré, J.S. Sidhu, N. Sinha, and P. Stanfield (eds.). Handbook of fruit and vegetable flavors. John Wiley and Sons, New York, NY.

Pomerleau, J., K. Lock, C. Kenai, and M. McKee. 2004. Effectiveness of interventions and programmes promoting fruit and vegetable intake. World Health Organization. Background paper for the Joint FAO/WHO Workshop on Fruit and Vegetables for Health, 1-3 Sept. 2004, Kobe, Japan.

Pomerleau, J., K. Lock, C. Kenai, and M. McKee. 2005. Interventions designed to increase adult fruit and vegetable intake can be effective: A systematic review of the literature. J. Nutr. 135:2486-2495

Resnicow, K., A. Jackson, T. Wang, A.K. De, F. McCarty, W.N. Dudley, and T. Baranowski. 2001. A motivational interviewing intervention to increase fruit and vegetable intake through black chuches: Results of the Eat for Life trial. Amer. J. Public Health 91:16861693.

Shenoy, S.F., A.G. Kazaks, R.R. Holt, H.J. Chen, B.L. Winters, C.S. Khoo, W.S. Poston, C.K. Haddock, R.S. Reeves, J.P. Foreyt, M.E. Gershin, and C.L. Keen. 2010. The use of a commercial vegetable juice as a practical means to increase vegetable intake: A randomized controlled trial. Nutr. J. 9:1-11.
Simon, P.W., L.M. Pollak, B.A. Clevidence, J.M Holden, and D.B. Haytowitz. 2009. Plant breeding for human nutritional quality. Plant Breed. Rev. 31:325-392.

U.S. Census Bureau. 2012. Statistical abstracts of the United States. Table 1242. Retail sales and household participation in lawn and garden activities: 2005 to 2010 . <http://www.census.gov>.

U.S. Department of Agriculture, Agricultural Research Service. 2012. USDA Nutrient Database for Standard Reference, Release 26. Nutrient Data Laboratory home page. <http://ndb.nal. usda.gov/ndb/search/list>.

U.S. Department of Agriculture and U.S. Department of Health and Human Services. 2010. Dietary Guidelines for Americans, 2010. 7th ed. U. S. Government Printing Office, Washington, DC, Dec. 2010. <http://www.chpp.usda.gov/ dgas2010-policydocument.htm $>$.

White, P.W., J.E. Bradshaw, M. Finlay, B. Dale, G. Ramsay, J.P. Hammond, and M.R. Broadley. 2009. Relationships between yield and mineral concentrations in potato tubers. HortScience 44:6-11.

World Health Organization. 2003. Diet, nutrition and the prevention of chronic diseases. Report of the joint WHO/FAO expert consultation. WHO Technical Report Series, No. 916. 